\title{
RESENHA
}

\section{Reprodução da Estrutura de Casta Racial na Sociedade Estadunidense}

ALEXANDER, Michelle. A nova segregação: racismo e encarceramento em massa. Tradução de Pedro Davoglio; Revisão técnica e notas Silvio Luiz de Almeida. 1.ed. São Paulo: Boitempo, 2017.

\section{Waleska Miguel Batista ${ }^{1}$}

${ }^{1}$ Advogada, Mestre em Sustentabilidade pelo Programa de Pós-Graduação Strict Sensu pela PUC-Campinas. E-mail: mbwaleska@gmail.com. ORCID: https://orcid.org/00000001-6700-9577.

\section{Frantz Rousseau Déus ${ }^{2}$}

2 Doutorando em Sociologia pelo Instituto de Filosofia e de Ciências Sociais- IFCH UNICAMP. E-mail: frantzrousseaudeus@yahoo.fr. ORCID: https://orcid.org/0000-00023073-3796.

Resenha recebida em 20/01/2019 e aceita em 20/02/2019.

\section{$(\mathrm{cc}) \mathrm{EY}$}

This work is licensed under a Creative Commons Attribution 4.0 International License. 


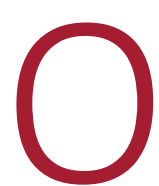

livro "A Nova Segregação: racismo e encarceramento em massa", de Michelle Alexander, publicado pela editora Boitempo, narra que apesar das conquistas do movimento de Direitos Civis, a partir de 1950, nos Estados Unidos da América, o racismo adotou nova forma de manifestação, dando continuidade à reprodução da desigualdade racial.

Michelle Alexander é advogada, militante e acadêmica na área dos direitos civis e professora universitária, bem como desenvolve pesquisas e artigos científicos a respeito de raça e justiça criminal, tendo sido uma das protagonistas do documentário "A 13a emenda", dirigido por Ava Duvernay.

"A Nova segregação: racismo e encarceramento em massa" possui introdução e seis capítulos: 1) O renascimento das castas; 2) O encarceramento; 3) A cor da justiça; 4) A mãe cruel; 5) O Novo Jim Crow; 6) Desta vez, o fogo. Estes estão conexos a ponto de ficar evidente o argumento de que o estigma da desigualdade racial, causa marginalização ou exclusão social, reforçada pela guerra às drogas e, por fim, causa encarceramento em massa dos negros.

A autora apresenta o argumento de que o sistema criminal sempre esteve empenhado em manter normalizada a justiça criminal com base na hierarquia racial historicamente consolidada dos Estados Unidos, que coloca os negros e os latinos como incivilizados, criminosos e vadios, enquanto que os brancos como honestos, civilizados e trabalhadores. Para essa estrutura social a autora utiliza a expressão casta racial. ${ }^{1}$

No período de vigência formal da Jim Crow, os negros eram impedidos de ocupar e transitar em determinados espaços da cidade, não podiam votar e tinham maior dificuldade para aquisição de imóveis ou móveis, bem como podiam estudar apenas nas escolas específicas para negros. A relação profissional e interpessoal entre brancos e negros era socialmente regulada e, em regra, juridicamente proibida.

$\mathrm{O}$ argumento de desigualdade racial é confrontado pelo motivo de o povo americano ter eleito para a presidência o homem negro Barack Obama, em 2008. Mas a autora afirma que "o atual sistema de controle depende da excepcionalidade negra", visto que tentam combater a existência do racismo apenas pelo fato de haver uma pessoa da minoria em determinado lugar como sendo de brancos. Outra questão

\footnotetext{
${ }^{1}$ A autora explica "Eu uso a expressão casta racial neste livro do modo como ela é usada na linguagem comum para denotar um grupo racial estigmatizado e preso em uma posição de inferioridade pelo direito e pelos costumes. O Jim Crow e a escravidão foram sistemas de casta racial. E o atual sistema de encarceramento em massa também o é." (ALEXANDER, 2017: 50).
} 
abordada pela autora é que não é porque a pessoa faz parte da minoria, que as decisões e atitudes contribuem para o combate do sistema de casta racial. ${ }^{2}$

A partir desses entendimentos, a autora explicita que as legislações do sistema criminal norte-americano foi a forma utilizada para reprimir a população negra, a tal ponto que os linchamentos dos negros, foi normalizado no tecido social apontando os negros como criminosos, colocando-os como reféns do direito penal. Então, o rótulo determinado para subalternação desse grupo passou a ser a cor da pele, sob a camuflagem de cumprimento do dever legal contra a criminalidade.

As leis de combate ao crime, e no caso, desse livro, especificamente, a lei de drogas, foi utilizada para manter os negros na condição de criminosos, enquanto que os brancos ficam livres de qualquer monitoramento policial. Esse paradigma foi implantado em razão do racismo institucional que tem uma abordagem importante nas escolas, no sistema judicial e nos meios de comunicação (HART, 2014: 24). ${ }^{3}$

A autora destaca que a busca por justiça, estimulada também por séries americanas como Law \& Order (Lei e Ordem) e S.W.A.T, em que os policiais brancos, utilizam todos meios possíveis para garantir que os supostos criminosos sejam condenados pelo tribunal, consolidam o imaginário social no sentido de que é a melhor (se não única) forma de se combater o crime que, em regra, acontece apenas nas comunidades negras ou latinas. ${ }^{4}$

Considera-se que a periferia composta por pessoas negras e latinas é o local em que o crime existe, rotulando todos os que estão ali como criminosos ou futuros criminosos, sem qualquer prova de que há algum ato criminoso que foi praticado.

Consequentemente, o perfil dos suspeitos a abordagem, busca ou revista dos policiais sempre é dos negros e latinos, mesmo sem qualquer evidência de prática criminosa, é socialmente normalizado, quando não legalmente autorizado que essas buscas possam acontecer pela discricionariedade do policial. Ou seja, não há regras especificas para determinar as investigações ou revistas que acontecem pela intuição (ou, se preferir, arbítrio) do policial.

\footnotetext{
2 "[...]sistema de castas raciais não exigem hostilidade racial ou intolerância aberta para prosperarem" (ALEXANDER, 2017: 52)

3 Para saber melhor sobre o tripé dos fundamentos do racismo ler a resenha do livro $O$ que é racismo institucional (BATISTA, 2018).

"O "punitivismo" e a "hostilidade" contra os negros acaba sendo preparado, mesmo que a pessoa alegue não ter preconceitos. Os estereótipos são formados por imagens ou sugestões verbais em face dos negros (ALEXANDER, 2017: 170).
} 
Estas foram as estratégias utilizadas pelos governos de estado e da presidência para mostrar o quão duros são no combate aos crimes e aos criminosos, de modo que "financiar defensorias públicas e pagar advogados privados para defender acusados de crimes têm recebido baixa prioridade" (ALEXANDER, 2017: 140)..$^{5}$

A autora aponta que o estigma de negro como criminoso faz com que apenas esse grupo seja alvo dos policiais, de forma que o combate às drogas focaliza majoritariamente nesse grupo, como se os negros fossem naturalmente violadores da lei.

Em razão da casta racial, são ignorados os dados da Pesquisa Nacional Domiciliar dos usuários de drogas, que constatou que o percentual de alunos brancos e negros do ensino médio que usam maconha é idêntico. A pesquisa relatou que em 2000, os jovens brancos entre doze e dezessete anos tinham um terço a mais de chances de vender drogas do que os jovens afro-americanos. ${ }^{6}$

Apesar disso, a Guerra às Drogas foi e ainda é, a principal arma de dominação do racismo, porque o traficante ou o criminoso sempre é caracterizado como negro, exigindo a este a punição mais rígida se comparada com a eventual prisão de um branco (ALEXANDER, 2017: 170-171). ${ }^{7}$

O Neurocientista Carl Hart, homem negro, que possui três filhos, dois em idade com maior potencial de sofrer ações de violência por parte da policial, afirmou que "eu me preocupava o tempo todo com a possibilidade muito concreta de que os meus próprios filhos entrassem na mira dos agentes da lei por corresponderem à descrição de um usuário de drogas ou por alguém achar que estavam sob efeito de drogas" (HART, 2014: 296).

O fato de ser negro coloca esses homens e mulheres em uma condição de inferiorização, mas a lei contribui para a reprodução dessa condição ao determinar que

\footnotetext{
5 "Aproximadamente $80 \%$ dos réus em processos criminais são indigentes e, por isso, incapazes de contratar um advogado. Além disso, nosso sistema de defensores públicos é lamentavelmente insuficiente." (ALEXANDER, 2017: 140).

${ }^{6} \mathrm{~A}$ autora ainda afirma que é um mito que os brancos compram drogas de negros, ou que vão comprá-las nos guetos. Isso foi uma estratégia pra marginalizar inclusive o espaço de vivência dos negros, porém na verdade, brancos compram drogas de brancos; negros de negros e estudantes universitários de estudantes universitários (ALEXANDER, 2017: 158).

${ }^{7} \mathrm{O}$ fato de os policiais afirmarem que revistariam um garoto branco no gueto vestindo calças largas é usado para justificar que a discricionariedade policial não tem determinação de raça. Todavia, se os guetos foram construídos já como uma forma de controle social dos negros e segregação, dificilmente há brancos nesse espaço. E até o fato de revistarem no gueto e não em repúblicas universitárias em busca de drogas demonstra que a não haver imparcialidade no momento das buscas. (ALEXANDER, 2017:200).
} 
as pessoas presas sejam impedidas de exercer o direito de voto e de receber benefícios do governo. Tendo em vista que os presos nesse combate as drogas são massivamente negros, estes acabam relegados às piores formas de sobrevivência, pois sequer empregos the são concedidos, pois a discriminação contra ex-presos é praticada de forma normalizada. Com isso os negros que estavam presos, ao saírem não são ressocializados, independentemente do tempo que ficaram preso. ${ }^{8}$

A autora afirma que o encarceramento em massa trouxe expansão econômica para o governo, da mesma forma que a escravidão, por isso a população carcerária amplia. Não é uma questão de aumento do crime, mas sim a imposição de punitivismo por "crimes de drogas" praticados pelos negros.

Como resultado do racismo nos Estados Unidos, a população negra foi o alvo das políticas de combate ao crime, por isso é o grupo com maior número de pessoas nos presídios. Estes lucram com o aumento da população carcerária.

O encarceramento em massa foi normalizado e todos os estereótipos e suposições raciais que deram origem ao sistema são agora abraçados (ou pelo menos internalizados) por pessoas de todas as cores, de todas as trajetórias de vida e por cada um dos principais partidos políticos. (ALEXANDER, 2017: 261)

Com base nas pesquisas realizadas, a autora afirma que o combate as drogas sequer era uma necessidade de urgência do Estado, pelo menos como política de combate ao crime, porque a quantidade de droga apreendida é pequena. Outro ponto colocado é que a maconha sequer causa danos tão agressivos como dirigir alcoolizado.

Nesse sentido, Hart (2014: 307-308) relatou que as políticas de drogas são erradas a partir do momento que ignoram que as punições mais rígidas pelo uso, posse ou venda de drogas não reduz a violência.

As leis de drogas são racialmente neutras, mas a sua aplicação é discriminatória. Isto contribui com o aumento de pessoas presas, o que corrobora com a expansão empresarial da privatização dos presídios. Quer dizer, o investimento está no aumento de vagas em prisões, que para ter retorno pelo investimento aumenta o índice de sujeitos encarcerados.

\footnotetext{
${ }^{8} \mathrm{~A}$ existência de registro criminal bloqueia quase todos os direitos de cidadania dos ex-presos. Por isso a autora narra que ao sair da prisão ou aceitar um acordo com a promotoria para denunciar a prática de outros crimes terá consequências piores do que a própria prisão. Os ex-presos serão excluídos permanentemente. (ALEXANDER, 2017: 214). "A permanência do exílio social é muitas vezes mais difícil de ser enfrentada. Para muitos, parece inconcebível que, por um pequeno crime, você possa estar sujeito a discriminação, desprezo e exclusão pelo resto de sua vida."(ALEXANDER, 2017: 240).
} 
Angela Davis (2018: 57-64) explicitou que o complexo criminal americano é estruturado pela organização G4S que afirma promover segurança para todo o mundo, mas, na verdade, promove a repressão contra minorias e utiliza táticas de tortura e discriminatórias, tudo sob a falácia de que busca a "segurança" com a privatização de serviços antes realizados pelo Estado. Com isso, "as pessoas trans de minorias étnicas formam o grupo com maior probabilidade de ser detido ou preso. O racismo alimenta a manutenção e a expansão do complexo industrial-prisional" (DAVIS, 2017: 64).

Assim, ao investigar a nova segregação, racismo e encarceramento em massa na sociedade norte-americana, a Alexander (2017) não deixa dúvida de que a forma como o Estado norte-americano lida com essa problemática, na verdade, segue uma lógica que prejudica os negros. A atribuição da criminalidade, bem como do tráfico de drogas a uma casta racial específica (pessoas negras) faz com que o negro seja tratado "como problema".

O olhar do negro como problema é muito datado na sociedade estadunidense, tanto que Du Bois (2007 [1903]) na sua obra The Souls of Black Folk já tinha analisado a condição do negro nesta sociedade. Du Bois, na sua época, muitas vezes foi constrangido a responder a pergunta: “Como se sente sendo um problema?"9 De acordo com Bernadino-Costa (2018: 254) Du Bois não respondeu a essa pergunta porque sabia que não era um problema do negro americano, "mas sim dos princípios fundamentais que embasam a sociedade norte-americana, que estabelecera uma linha de cor separando negros de brancos". Desde então este autor se lançou na luta para inverter essa visão, isto é, ele não fala de "problema do negro", mas de problemas sociais que afetam as pessoas negras na sociedade americana (BERNADINO-COSTA, 2018: 254).

A análise de Du Bois continua sendo relevante para pensar os problemas sociais que afetam os negros nos Estados Unidos. Desta forma, o trabalho de Michelle Alexander evidencia que a linha de cor percebida por Du Bois continua desempenhando um papel importante no tratamento que o negro recebe na sociedade em questão. $\mathrm{A}$

\footnotetext{
${ }^{9}$ Essa pergunta segundo Du Bois aparece de diversas formas, de maneira mascarada ao afirmar: "entre mim e o outro existe sempre uma questão não respondia: não respondida por alguns em virtude de um sentimento de delicadeza, por outros pela dificuldade de uma correta formulação. Todos, entretanto, giram ao redor disto. Eles se aproximam de mim de uma maneira meio hesitante, olham-me curiosamente ou com compaixão, e então, ao invés de dizerem diretamente, "como se sente sendo um problema?" Eles dizem, eu conheço um excelente homem de cor na cidade; ou, eu lutei em Mechanicsville; ou, essas ofensas sulistas não fazem seu sangue ferver? Diante destes, eu sorrio, ou apresento-me interessado, ou abrando o fervor, como a ocasião requer. Para a tal questão, como se sente sendo um problema? Eu raramente respondo" (DU BOIS, 2007 [1903]: 2).
} 
legislação do sistema criminal americano analisada por ela é um exemplo disso, visto que é utilizada para reprimir a população negra. ${ }^{10}$

Os homens negros capturados pelo sistema criminal de justiça americano perdem direitos políticos e sociais, mas o que eles perdem em si é a cidadania. 0 estigma de criminoso é o mal carregado para toda a vida, de maneira que Alexander (2017) narra que a vida após sair da prisão é pior do que o encarceramento.

Concluindo o livro, Alexander (2017) enfatiza que o encarceramento em massa faz com que os negros sejam transformados em inúteis, pois para a sociedade americana, eles não servem para praticar mais nenhum ato de cidadania.

A discriminação em face dos ex-presos está socialmente legalizada, tanto para brancos quanto para negros. Todavia, o número destes é imensamente superior ao daquele, de modo que não se pode alegar a inexistência do fator racial para determinação do sistema carcerário. Nesse sentido, deve-se combater a neutralidade racial, que define que se os negros estão presos é porque escolheram esse destino, negando a existência do racismo. Porém, como supramencionado, é exatamente a raça que determina que os negros são criminosos.

No mais, o livro é relevante para a atualidade porque discute a privatização do sistema prisional, o racismo estrutural e o estabelecimento de lugar de negros. Além disso, o livro expõe que a criminalização das drogas é mais uma estratégia para justificar a racionalidade de inferiorização dos negros, ampliando o encarceramento destes.

\section{Referências Bibliográficas}

ALEXANDER, Michele. A nova segregação: racismo e encarceramento em massa. Tradução de Pedro Davoglio; Revisão técnica e notas Silvio Luiz de Almeida. 1.ed. São Paulo: Boitempo, 2017.

BERNARDINO-COSTA, Joaze. Convergências entre Intelectuais do Atlantico Negro: Guerreiro Ramos, Frantz Fanon e Du Bois. In: BERNARDINO-COSTA, J; MALDONADO-TORRES, N. ; GROSFOGUEL, R. (Orgs). Decolonialidade $e$ Pensamento Afrodiaspórico. Belo Horizonte: Autentica Editora, 2018.

${ }^{10}$ Alexander (2017: 262) afirma que "imagens de homens negros algemados têm sido um tema regular dos noticiários policiais. Nós sabemos que um grande número deles está trancado em jaulas. Na verdade, é precisamente porque sabemos que as pessoas pretas e pardas estão muito mais propensas a serem aprisionadas que nós, como nação, não nos importamos muito com isso". 
BATISTA, Waleska Miguel. A inferiorização dos negros a partir do racismo estrutural. Revista Direito e Práxis, v. 9, n. 4, 2018, p. 2581-2589. Disponível em: https://www.e-publicacoes.uerj.br/index.php/revistaceaju/article/view/36867.

Acesso em: 27 jan 2019. DOI: 10.1590/2179-8966/2018/36867.

DAVIS, Angela. A liberdade é uma luta constante. Tradução de Hecu Regina Candiani. 1.ed. São Paulo: Boitempo, 2018.

DU BOIS, W. E. B. The Souls of Black Folk. Oxfor/New York: Oxford University Press, 2007 [1903].

HART, Carl. Um preço muito alto: a jornada de um neurocientista que desafia nossa visão sobre as drogas. Tradução de Clóvis Marques. 1.ed. Rio de Janeiro: Zahar, 2014.

Sobre os autores

Waleska Miguel Batista

Advogada, Mestre em Sustentabilidade pelo Programa de Pós-Graduação Strict Sensu pela PUC-Campinas. E-mail: mbwaleska@gmail.com.

Frantz Rousseau Déus

Doutorando em Sociologia pelo Instituto de Filosofia e de Ciências Sociais- IFCH UNICAMP.E-mail: frantzrousseaudeus@yahoo.fr

Os autores contribuíram igualmente para a redação da resenha. 
ERRATA

na página 2296 e 2303, e no rodapé das páginas 2296-2303:

Onde se lia:

"Franz Rosseau Déus"

Leia-se:

"Frantz Rousseau Déus"

na página 2303:

Onde se lia:

"Sobre as autoras"

Leia-se:

"Sobre os autores"

na página 2303:

Onde se lia:

"As autoras contribuíram igualmente para a redação da resenha."

Leia-se:

"Os autores contribuíram igualmente para a redação da resenha."

Revista Direito e Práxis (2020) 11(2): 1467 